\title{
CONSERVATION OF HISTORIC BUILDINGS IN A SEISMIC ZONE : A NEW ZEALAND PERSPECTIVE
}

\author{
Ian Bowman*
}

\begin{abstract}
SUMMARY
Following the accepted principles and practice of conservation of historic buildings in New Zealand is complicated by the proximity to earthquake activity. The author's own research, outlined in this article, draws some conclusions.
\end{abstract}

\section{INTRODUCTION}

"Conservation in a Seismic Zone" was the tonic of my dissertation presented for an M.A. in Builáing Conservation Studies from the Institute of Advanced Architectural Studies of the University of York [1]. Anti-seismic engineering in New Zealand is well advanced whereas the serious study of conservation is very recent and consequently so is the area where these two disciplines meet. This was the reason for my choice of study and in this article I intend to cover the most important conclusions of my dissertation. These are; defining the problems in assessing seismic risk in historic buildings, the conclusions of international conservation organisations, and what measures can be implemented immediately in New Zealand. But, firstly $I$ will begin with an explanation of why it is necessary to have a concern for historic buildings and a concern for the measures selected for conservation.

\section{HISTORIC BUILDINGS: A DEFINITION}

Historic buildings are, in international conservation terms, "built cultural heritage" or "cultural property". These relatively few buildings with the necessary qualities are selected in New Zealand by the New Zealand Historic Places Trust through its classification system. Each is worthy of protection for future generations because of the enjoyment, experience and education which these buildings provide - exactly the same reasons for conservation of our natural heritage.

These buildings have a value beyond what can be directly appreciated such as design, building technology, techniques and use of materials. Political, social, economic and religious values can be appreciated - in other words, historic buildings reflect the formation and changes of our

Architectural Conservator, Architect, Works, Wellington. culture which make them worth our concern for their survival and with their historic integrity intact.

\section{ASSESSMENT OF RISK}

The various conservation processes have evolved to ensure maximum historic value is retained and if possible enhanced. Conservation in a seismic zone presents something of a dilemma that is not faced in other areas. The process of conservation selected, such as strengthening, to ensure survival from earthquake attack may destroy its essential value, and its cultural significance will be lost. Correct assessment of seismic risk and appropriate measures to rectify inadequate strength levels discovered will help mitigate this dilemma.

The need for strengthening of historic buildings lies very much with the methods of assessment adopted, and this provides one of the main problems in conservation in seismic zones. Accurate assessment of seismic risk to each building is the most important method of ensuring selection of adequate strengthening measures where required. The NZNSEE Recommendations for Earthquake Risk Buildings [2] covers many of the steps necessary for the assessment of risk for historic buildings. Examining the building configuration, building materials and building condition for most building types are equally important when considering historic buildings. However. recommended strengthening levels and periods for strengthening can not be applied without thought to conservation standards.

Historic building materials can not also necessarily be compared with modern materials. An existing building or earth can not easily be assessed because of a lack of knowledge as to correct design or use of materials. Turkey is one country where legislation exists for design of new earth buildings in seismic zones and their specifications can be used as a basis for examining historic earth buildings retrospectively. 
The Californian State Historic Building Code [3] recognises some of these difficulties in applying new design criteria to historic buildings. This code can be used as an alternative to standard building codes and appears to allow considerable latitude in interpretation of the requirements according to the professional judgement of those using the code. An important recognition of the strength of historic buildings is given in the code which states:

"where no distress is evident the structure may have assumed to have withstood the test of time".

Such a pragmatic approach has considerable merit assuming buildings have been well maintained. At least one New Zealand expert earthquake engineer approves of this assumption.

Where historic buildings are at most disadvantage is the scientific testing of historic structures to determine the strength levels. At the moment it appears that present methods are not completely reliable and the survival of historic buildings is at risk because of this inadequacy. Until such time as methods have been devised to accurately test the strength of an historic building the Californian approach should be adopted.

\section{INTERNATIONAL GUIDELINES FOR STRENGTHENING}

Having assessed the strength of an historic building how, then, should any required work be carried out? As with all conservation practice each property is treated on an individual basis. There are, however, guidelines as to methods and principles of working and an important area in my dissertation was the conclusions of international conservation agencies, ICOMOS, (the International Council of Monuments and Sites) and ICCROM (the Rome Centre), on the conservation of historic buildings in seismic zones.

The main meetings that discussed this issue were the "Meeting of Experts on the Protection of Monuments in Seismic Areas" in 1977 [4], "Seminar-Cum-Training-Course on the Protection of Monuments in Seismic Areas" in 1979 [5], the ICOMOS seminar on "International Experience in the Conservation of Cultural Property in Earthquake zones" [6] of 1977, and the "International Meeting of Experts on the Protection of the Cultural Heritage Against Violent Natural Phenomena and their Consequences" of 1983 [7].

Most recommendations accepted that conservation ought to be carried out according to the Venice Charter of 1966 in which standards of conservation for historic buildings and archeological sites were determined. (See Appendix). Awareness of the Venice Charter in New Zealand has been very limited until recently and carrying out of conservation has suffered. Consequently this recommendation has significance for all who practice conservation in New Zealand.
A second common recommendation is the preparation of seismic hazard maps for each building or structure. This ensures that the delineation of risk to each property through micro-zoning is known and understood and the hope is that appropriate measures would follow to counter the danger. The existing $A B$ and $C$ zones of seismic hazard have been criticized as being too unspecific and if the suggested map of regionalised earthquake risk, as published in the Proceedings of the 1981 Napier Large Earthquake Conference are accepted, seismic risk to historic buildings and structures could be incorporated at this time. One meeting suggested a 100 year return period earthquake be considered as the design earthquake for historic buildings. Also recommended was the use of accelerographs on each building to collect information on the seismic response of each building.

A most important conclusion of each meeting was that existing standard building codes and legislation should not be applied to historic buildings. Adherence to such codes has universally been found to be detrimental to the conservation of these buildings and even more so with regard to anti-seismic strengthening. Each building should be considered on its merits and strengthening and repair work be carried out accordingly. Where a greater risk to life and building results, then this should be accepted and other measures be taken to counter the risk to life. Enormous camage has already been wrought by the Local Government Amendment Act on the stock of historic buildings, in Wellington in particular.

With respect to methods and techniques of upgrading and repairs to historic buildings, the 1977 Meeting of Experts recommended:

"4 All interventions designed to strengthen monuments against future earthquakes should respect the character and integrity of the original structure. They should, as far as possible, use similar materials. Where different materials are substituted, care should be taken to see that the strength or stiffness are not incompatible with those of the original structure which will usually be less stiff and more accommodating to earthquakes and other long term movements than contemporary structures. It is particularly necessary to consider the effects any modifications of the stiffness on the dynamic approach.

" 5 The final choice of the approach to be adopted should be made only by a specialist after proper appraisal (consistent with the scale of operations and the resources available) of alternative and with some eye to the future. In general, interventions that can be undertaken in stages, that can be controlled by monitoring their effects, and that can be repeated, reinforces, or reversed as necessary, are preferable to those that are irreversible, "once and for all", and 
call for a complete advance commitment to a single course of action. Whatever is done should be fully documented and the records deposited with a competent authority for future reference."

The most significant articles to be considered in the Venice Charter when undertaking anti-seismic conservation work are $5,6,9,10$ and 16 . Articles 5 and 6 restricts alterations for whatever need to those not requiring demolition of spaces and decoration of the historic plan. Structural systems too are considered as important elements and are as significant as any other element to be conserved in an historic building. Retention of the existing structural system should be an essential part of the upgrading proposed, enhanced if necessary. Article 9 accepts the need for new work but where, as described elsewhere in the Charter, it is compatible in scale, mass, texture, and colour, yet is recognisable on close inspection as new work.

A further conclusion was that adequate legislation and funding were considered as essential prerequisites for conservation. Existing legislation is hopelessly inadequate to ensure protection of New Zealand's historic buildings but it is to be hoped that a promised revision of the existing act will rectify this. Incorporated into the proposed new legislation should be provision and encouragement for emergency and long term conservation measures and one most important part of the conservation process, and which ought to receive assistance above all, is maintenance. A well maintained building will perform better under earthquake attack than one which has been poorly maintained. Cyclical preventative maintenance programmes should be implemented under normal conditions, and were financial assistance given, costs for conservation would be significantly reduced.

\section{EMERGENCY MEASURES}

A final main conclusion of each meeting was the call for appropriate emergency measures be taken by central and local authorities and this provides my final point as to what can be implemented immediately in New Zealand. The recent Bay of Plenty earthquake showed the almost complete exclusion of interest in historic buildings after a major earthquake where measures vital to the survival of our cultural heritage were needed to be taken. My own efforts to visit the area as an expert in building conservation were met by a complete lack of support and consequently I only learned of the results of the earthquake second hand. As far as I am aware no building conservation expert visited the area.

The first recommendation in an emergency is the ready identification of each historic building. A local authority listing or the New Zealand Historic Places Trust classification list would provide such identification and emergency organisations such as Civil Defence should have a copy on hand. An Architectural conservator would be appointed to safeguard each building in an emergency. He or she would visit each building and classify damage occurred and identify each to the emergency organisation. Damage assessment forms have been designed and used in several major earthquakes to quickly and easily assess damage.

The Hague symbol has been used effectively to distinguish cultural property to minimise damage and assist repair work. This symbol describes the extent of damage as well as identifies the building as historic. Such a building would be prevented from being demolished and all debris from the building would also be protected. Valuable historic fabric necessary in the repair work is then not lost.

Criticism of Civil Defence has been made by insurance assessors of the recent Bay of plenty earthquake in which all chimneys, regardless of condition, were required to be demolished. Such unnecessary destruction would be avoided for historic buildings if this symbol were used. [8]

Having identified historic buildings and their condition emergency measures can then be carried out. Removal of movable cultural property can be organised, documenting each item and its temporary location. Weather protection of the building itself can be effected by using tarpaulins, while temporary securing of the building from further seismic movement can be carried out using post stressed strapping. These would be positioned at each floor level, tops of walls, haunches and vaults. This form of protection is more beneficial than temporary shoring which can transmit future shocks directly onto the structure and can be difficult to position. Each opening would be braced.

In order that these measures can be effected quickly, local or central disaster relief organisations should have materials and equipment at hand. The 1979 Seminar recommended that a building conservation expert be appointed to civil defence committees to ensure safety of buildings during an emergency and to regularly inspect the buildings.

\section{CONCLUSION}

In discussing some relevant areas of my dissertation I hope I have introduced or clarified some areas of concern for conservation of New Zealand's stock of historic buildings. New Zealand certainly has the expertise in engineering and more recently in building conservation and $I$ am hopeful that a combination of these skills will enhance our level of conservation. New Zealand has recently joined ICCROM and a New Zealand committee of ICOMOS has recently been established. Both of these organisations have a concern for conservation in a seismic zone and provide information and expertise to member countries, particularly in problems associated with earthquake areas. Having been at least 15 years behind other countries in conserv- 
ation expertise, legislation, assistant, and international involvement, I am hopeful that this position will improve.

\section{REFERENCES}

1. Bowman, I.A., "Conservation in a Seismic Zone". Unpublished Thesis, University of York, 1985.

2. New Zealand National Society for Earthquake Engineering, "Earthquake Risk Buildings, Recommendations and Guidelines for Classifying, Interim Securing, and strengthening", 1985.

3. State of California Documents Section, "State Historical Building Code", State of California, title 24, Building Standards, Part 8, 1981 .

4. UNESCO and ICOMOS, "Meeting of Experts on the Protection of Monuments in Seismic Areas, December 1977", as printed in UNESCO, ICOMOS, and Conseja Nacional para le protection de la Antigua Guatemala, Final Report.
5. UNESCO, ICOMOS, and Conseja Nacional Para le Protection de la Antigua Guatemala, "Seminar-Cum-Training Course on the Protection of Monuments in Seismic Areas, November, 1979", Final Report.

6. ICOMOS, "International Experience in the Conservation of Cultural Property in Earthruake Zones, Udine, April 1977". Second Draft, ICOMOS Centre de Documentation.

7. UNESCO and the Yugoslav Commission for UNESCO. "International Meeting of Experts on the Protection of the Cultural Heritage Against Violent Natural Phenomena and their consequences", Skopje. January/February 1983, Final Report.

8. N.z. Institute of Quantity Surveyors Inc., Seminar Bay of Plenty Earthqake, 30.9 .87

\title{
APPENDIX 1
}

ICOMOS

\section{International Council of Monuments and Sites}

\author{
INTERNATIONAL CHARTER FOR THE \\ CONSERVATION AND RESTORATION OF MONUMENTS AND SITES
}

Imbued with a message from the past, the historic monuments of generations of people remain to the present day as living witnesses of their age-old traditions. people are becoming more and more conscious of the unity of human values and regard ancient monuments as common heritage. The common responsibility to safeguard them for future generations is recognized. It is our duty to hand them on in the full richness of their authenticity.

It is essential that the principles guiding the presevation and restroration of ancient buildings should be agreed and be laid down on an international basis, with each country being responsible for applying the plan within the framework of its own culture and traditions.

By defining these basic principles for the first time, the Athens Charter of 1931 contributed towards the development of an extensive international movement which has assumed concrete form in national documents, in the work of ICOM and UNESCO and in the establishment by the latter of the International Centre for the study of the Preservation and the Restoration of Cultural property. Increasing awareness and critical study have been brought to bear on problems which have continually become more complex and varied; now the time has come to examine the charter afresh in order to make a thorough study of the principles involved and to enlarge its scope in a new document.

Accordingly, the IInd International Congress of Architects and Technicians of Historic Monuments, which met in Venice from May 25th to 3lst 1964, approved the following text:

\section{DEFINITIONS}

Article 1. The concept of an historic monument embraces not only the single architectural work but also the urban or rural setting in which is found the evidence of a particular civilisation, a significant development or an historic event. This applies not only to great works of art but also to more modest works of the past which have acquired cultural significance with the passing of time.

Article 2. The conservation and restoration of monuments must have recourse to all the sciences and techniques which can contribute to the study and safeguarding 
of the architectural heritage.

\section{AIM}

Article 3. The intention in conserving and restoring monuments is to safeguard them no less as works of art than as historical evidence.

\section{CONSERVATION}

Article 4. It is essential to the conservation of monuments that they be maintained on a permanent basis.

Article 5. The conservation of monuments is always facilitated by making use of them for some socially useful purpose. Such use is therefore desirable but it must not change the lay-out or decoration of the building. It is within these limits only that modifications demanded by a change of function should be envisaged and may be permitted.

Article 6. The conservation of a monument implies preserving a setting which is not out of scale. Wherever the traditional setting exists, it must be kept. No new construction, demolition or modification which would alter the relations of mass and colour must be allowed.

Article 7. A monument is inseparable from the history to which it bears witness and from the setting in which it occurs. The moving of all or part of a monument cannot be allowed except where the safeguarding of that monument demands it or where it is justified by national or international interests of paramount importance.

Article 8. Items of sculpture, painting or decoration which form an integral part of a monument may only be removed from it if this is the sole means of ensuring their preservation.

\section{RESTORATION}

Article 9. The process of restoration is a highly specialised operation. Its aim is to preserve and reveal the aesthetic and historic value of the monument and is based on respect for original material and authentic documents. It must stop at the point where conjecture begins, and in this case moreover any extra work which is indispensable must be distinct from the architectural composition and must bear a contemporary stamp. The restoration in any case must be preceded and followed by an archaeological and historical study of the monument.

Article 10. Where traditional techniques prove inadequate, the consolidation of a monument can be achieved by the use of any modern technique for conservation and construction, the efficacy of which has been shown by scientific data and proved by experience.

Article 1l. The valid contributions of all periods to the building of a monument must be respected, since unity of style is not the aim of a restoration. When a building includes the superimposed work of different periods, the revealing of the underlying state can only be justified in exceptional circumstances and when what is removed is of little interest and the material which is brought to light is of great historical, archaeological or aesthetic value, and its state of preservation good enough to justify the action. Evaluation of the importance of the elements involved and the decision as to what may be destroyed cannot rest solely on the individual in charge of the work.

Article 12. Replacement of missing parts must integrate harmoniously with the whole, but at the same time must be distinguishable from the original so that restoration does not falsify the artistic or historic evidence.

Article 13. Additions cannot be allowed except in so far as they do not detract from the interesting parts of the building, its traditional setting, the balance of its composition and its relation with its surroundings.

\section{HISTORIC SITES}

Article 14. The sites of monuments must be the object of special care in order to safeguard their integrity and ensure that they are cleared and presented in a seemly manner. The work of conservation and restoration carried out in such places should be inspired by the principles set forth in the foregoing articles.

\section{EXCAVATIONS}

Article 15. Excavations should be carried out in accordance with scientific standards and the recommendation defining international principles to be applied in the case of archaeological excavation adopted by UNESCO in 1956 .

Ruins must be maintained and measures necessary for the permanent conservation and protection of architectural features and of objects discovered must be taken. Furthermore, every means must be taken to facilitate the understanding of the monument and to reveal it without ever distorting its meaning.

All reconstruction work should however be ruled out a priori. Oniy anatylosis, that is to say, the reassembling of existing but dismembered parts can be permitted. The material used for integration should always be recognisable and its use should be the least that will ensure the conservation of a monument and the reinstatement of its form.

\section{PUBLICATION}

Article 16. In all works of preservation, restoration or excavation, there 
should always be precise documentation in the form of analytical and critical reports, illustrated with drawings and photographs.

Every stage of the work of clearing, consolidation, rearrangement and integration, as well as technical and formal features identified during the course of the work, should be included. This record should be placed in the archives of a public institution and made available to research workers. It is recommended that the report should be published.

The following persons took part in the work of the Committee for drafting the International Charter for the Conservation and Restoration of Monuments:

Mr. Piero Gazzola (Italy), Chairman

$\mathrm{Mr}$. Raymond Lemaire (Belgium), Reporter

Mr. José Bassegoda-Nonell (Spain)

$\mathrm{Mr}$. Luis Benavente (Portugal)

Mr. Djurdje Boskovic (Yugoslavia)
Mr. Hiroshi Daifuku (U.N.E.S.C.O.)

Mr. P.L. de Vrieze (Netherlands)

Mr. Harald Langberg (Denmark)

Mr. Mario Matteucci (Italy)

Mr. Jean Merlet (France)

Mr. Carlos Flores Marini (Mexico)

Mr. Roberto Pane (Italy)

Mr. S.C.J. Pavel (Czechoslovakia)

Mr. Paul Philippot (International Centre for the Study of the Preservation and Restoration of Cultural Property)

Mr. Victor Pimentel (Peru)

Mr. Harold Plenderleith (International Centre for the Study of the Preservation and Restoration of Cultural Property)

Mr. Deoclecio Redig De Campos (Vatican)

$\mathrm{Mr}$. Jean Sonnier (France)

Mr. Francois Sorlin (France)

Mr. Eustathios Stikas (Greece)

Mrs. Gertrud Tripp (Austria)

Mr. Jan Zachwatovicz (Poland)

Mr. Mustafa S. Zbiss (Tunisia)

The local address for ICOMOS is:

The Chairman,

ICOMOS N.Z. National Committee

13 Gibraltar Crescent

Parnel1

AUCKLAND 1

The local contact for ICCROM is the UNESCO office in Wellington. 

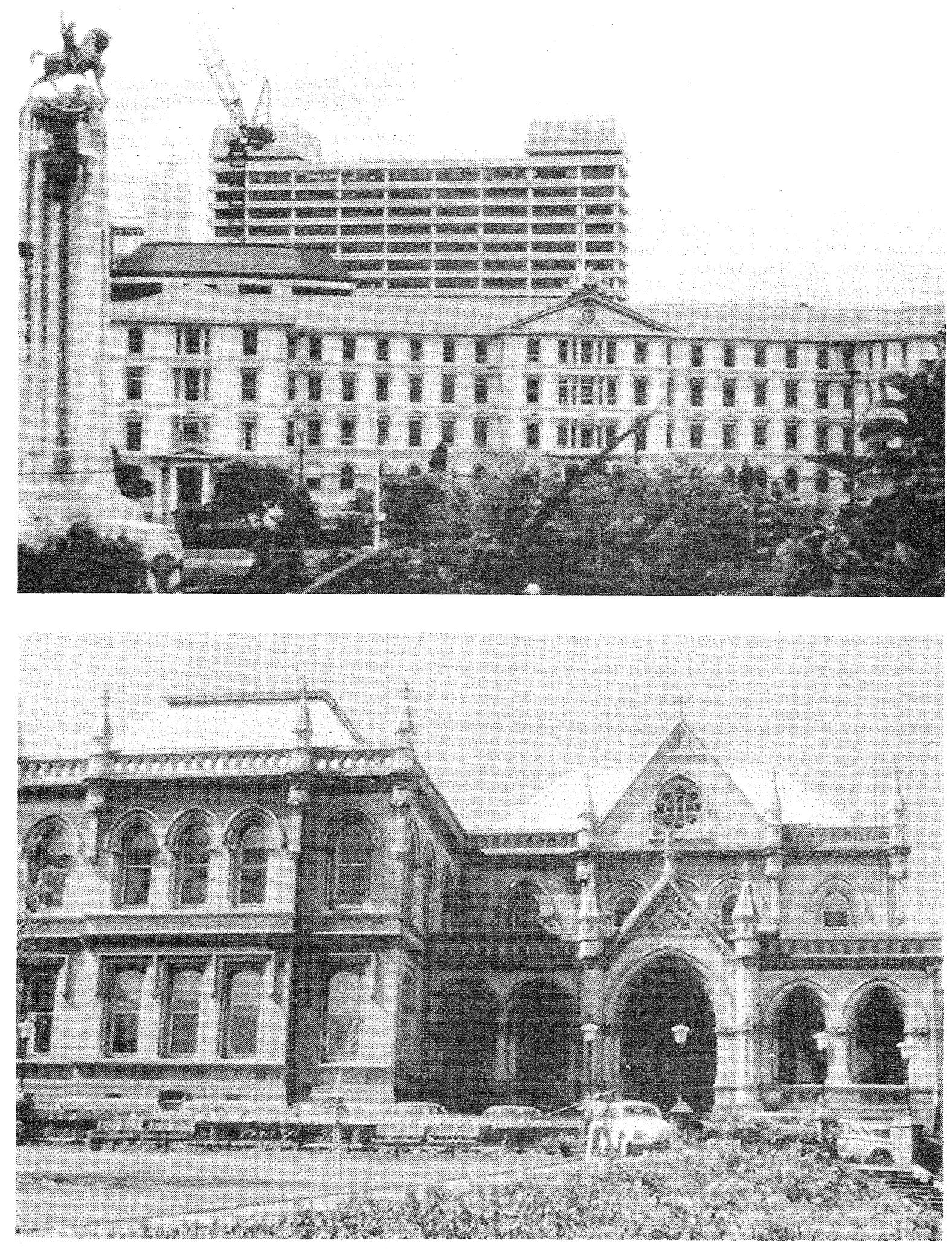

TYPICAL BUILDINGS FOR CONSERVATION:

(TOP) THE OLD GOVERNMENT BUILDINGS;

(BOTTOM) THE GENERAL ASSEMBLY LIBRARY BUILDING. 